\title{
Comprehension strategies used by the Islamic senior high school students during shadow reading
}

\author{
Arlina $^{1}$, Iskandar ${ }^{2}$ \\ ${ }^{1}$ Graduate Program, Universitas Negeri Makassar, Makassar, Indonesia \\ $e$-mail: arlinahamid.b2@gmail.com \\ ${ }^{2}$ English Department, Faculty of Languages and Literature, Universitas Negeri Makassar, Makasar, Indonesia \\ *e-mail: iskandar@unm.ac.id
}

\begin{abstract}
This research aims at finding out comprehension strategies used by the students during shadow reading. This research is qualitative research with classroom observation. This research is based on Vygotsky's sociocultural theory that involves scaffolding and zone of proximal development (ZPD). The data is analyzed through problem-solving as comprehension analysis. The comprehension strategies are focused on three aspects of reading namely phonological processing, word recognition, and syntactical processing. This research is restricted to the interactional phase of shadow reading and focused during reading only. The result shows that from those three focuses, there are six comprehension strategies. In the phonological processing, there are repairing incorrect utterance of partner and dividing a word into manageable sound. In the word recognition, there are implicitly asking for repetition to complete the task and giving repetition for incorrect word. In the syntactical processing, there are modifying input in manageable repetition and explicitly requesting repetition to complete the task. Those strategies help the shadower to complete the task. Thus, they can reach ZPD.
\end{abstract}

\section{Keywords:}

Comprehension strategies; shadow reading; Zone Proximal Development; sociocultural theory

\section{INTRODUCTION}

Comprehension is one of the essential components of reading. Reading aims at enabling students to obtain understanding; therefore there is no reading when there is no comprehension (Bolain, 2008). Reading is not only about fluency but also about how the readers comprehend what they have just read. People read a variety of texts such as signs, timetable, directories, maps, letters, tables, application forms, stories, textbooks, instructional, leaflets and the like to get facts, exchange ideas, enjoy their leisure time, express feelings, etc. When they read those kinds of texts, it is known that they want to obtain information from a subject. As Grellet (1981) states understanding a written text means extracting the required information from it as accurately and efficiently as possible. Thus, comprehension is important in reading a text to understand what they just have read.

Shadow reading is used to repeat and imitates after reading the text either selective or engaging in communication (Murphey, 2001). Shadow-reading could relief the students to figure out the text pairs interaction (de Guerrero \& Commander, 2013). In the procedures of shadow-reading itself, two phases should be paid attention by the lecturers; they are the interactional phase and non-interactional phase. In the interactional phase, consisting of a pair-based shadowreading and summarizing session. The students read aloud the text; repeat the sentences and reread it as a whole paragraph or passage. Whereas in the non-interactional phase, consisting of individual student writing of recall protocols. However, in this research, the researchers only implemented one step, that is interactional phases.

This research is grounded by Vygotskyan's sociocultural theory that involves a zone of proximal development (ZPD). Vygotsky (1980) defines ZPD as "the distance between the actual developmental level as determined by independent problem solving and the potential development as determined through problem-solving under adult guidance or in collaboration with more capable" (p.86). The definition reveals a condition where learners can solve their problems in learning through collaboration.

Some researchers has conducted research using Shadow Reading successfully. Commander and de Guerrero (2016) have done a study to identify and describe instances of imitation from a Vygotskyan perspective in an ESL classroombased shadow-reading activity. Specifically, they wanted to observe how learners working within their ZPDs were able to internalize and creatively reconstruct a story text through imitation, a process which impacted not only the learners' text comprehension and retention but also their linguistic development. They focus on two contexts of imitative behavior among second learner social. Many kinds of imitative behaviors, they are ranging from close copies to model transformation, along with proximate to overdue reproductions. The built-in, recursive structure of the shadow-reading task seemed effective in providing affordances for persistent, meaningful imitation and internalization of the second language exemplars besides story comprehension and retention.

\section{LITERATURE REVIEW}

Some researchers have done researches that focus on reading comprehension. Their findings are a contribution to improving English teaching, mainly reading comprehension. Some research findings have a close relation to this research. Sadeghi, Afghari, and Zarei (2016) researched to find out whether shadow reading as a means of internalization of meaning affects the reading ability of Iranian EFL learners. The sample of the research was 52 junior EFL learners from two universities. They were randomly assigned to experimental and control groups. To see if the learners were in a similar level of comprehension, the researchers used four reading passages with 20 Multiple Choice items as a pretest. Then, the 
researchers applied shadow reading in 10 sessions which the learners were required to listen and repeat the passage, then summarize what they had comprehended from the text. The results of the research showed that shadow-reading has significantly affected learners' comprehension. The results were also based on Vygotskyan theory which used shadowing as a means of meaningful imitation and interaction to facilitate comprehension among the learners. Thus, shadow reading and its sociocultural traits can be used as an appropriate means to promote reading comprehension all over the world.

Shafiei and Rahmany (2017) investigated the effect of shadowing with and without a written script on the Iranian EFL students' listening comprehension. Seventy-seven participants out of a population of ninety-nine students were randomly picked through the administration of Preliminary English Test (PET). The participants were three groups of intermediate level. The data were administered in a pre-test and a post-test schedule. The analysis of the test scores, using a one-way ANOVA, revealed that the experimental groups (A \& B) performed statistically better in the test. It also revealed that the shadowing with written script group performed statistically better than the without written script group. Hamada (2012) investigated the effective way of teaching listening through shadowing. Fifty-nine research subjects consist of thirtyseven male and twenty-two Japanese national university first-year students, majoring in education, nursing, and engineering participated in the study. The results of this study were the learners' listening comprehension skills improved after combining different difficulties of learning materials alternately.

There are many psychological approaches and perspectives related to the human mind. Vygotsky (1980) mentioned that there are two bases of human mind namely a lower level neurobiological base and a higher level cultural tool while the psychological approaches are categorized into two: natural science (mental activity) and mental processes (problemsolving, voluntary memory and attention, rational thought, planning, and meaning-making activity). Vygotsky claimed that reading comprehension is related to the development of a child's thinking and involves a complicated process. He also made a comparison between reading and mathematics that involves comprehension and problem-solving. Vygotsky mentioned this claim because of the crisis in psychology. Thus, Vygotsky used sociocultural to overcome the crisis. It is expected that the sociocultural theory can provide a solution to any problem in reading comprehension. In Vygotsky's sociocultural theory, there are two primary theoretical constructs namely scaffolding and zone of proximal development (ZPD). Vygotsky (1986) describes ZPD as the concept that relates to the distinction between what a child can do independently and what a child can do dependently. While, scaffolding refers to sociocultural interaction between a lower level learner and a higher level learner (Berk \& Winsler, 1995). Based on the previous related study, it is revealed that shadow reading is an excellent method to enhance listening and reading comprehension. Also, shadow reading can facilitate the teachers to find out strategies for their students to comprehend a text. Thus, the researchers are interested in researching the students' strategies to understand narrative text during shadow reading.

\section{METHOD}

This chapter consists of research design, variables, and operational definition, population, and sample, the research instruments, the procedure of collecting data, and technique of data analysis.

\subsection{Research Design}

In this research, the researchers used qualitative research. According to Mills and Gay (2015), qualitative research is the collection, analysis, and interpretation of comprehensive narrative as well as visual data to gain insights into a particular phenomenon of interest. Furthermore, the purpose of qualitative research focuses and deals with promoting a deep understanding of a specific phenomenon, such as the environment, a process, or even belief. This research used qualitative research to collect and analyze data which suitable with the purpose of the research to get information about the implementation of shadow reading using interactional phase at one of senior high school in South Sulawesi, Indonesia.

\subsection{Operational Definition}

To obtain a good understanding of this research, it is important to define terms related to this research. The terms are as follows:

- Comprehension strategies are strategies used by the students both the reader and the shadower to comprehend the text during the shadow reading process. The strategies here are based on comprehension-enabling talk analysis which focused on phonological processing, word recognition, and syntactical processing.

- Shadow reading is reading activity where students understand a text from their partner information and repeating or summarizing it with their word. The teacher asked the students to work in pairs. One of them become a reader, and the other one becomes a shadower.

\subsection{The subject of the Research}

This research applied a purposive sampling; the researchers selected a participant according to the needs of the study. In this research, the participants of the research were the second-grade students at one of Senior High School in South Sulawesi, Indonesia. The second grade consisted of 7 classes, and each class consisted of 37 students, while the total of the population is 259 students. The researchers took one class of them that consisted of 37 students. Moreover, the students of this class were selected as research participant because the English teacher recommended it.

\subsection{The instrument of the Research}

In this part, the researchers explain how the researchers determine the right method to collect the data with is to manage the instrument. In managing the instrument to collect the data should be seriously handled to get an accurate result. In this research, the researchers applied the Narrative text as the instruments. The text used in the study was based on Heyer (1987) story 'Lost and Found.' This text was selected because it contained many words, phrases, and syntactic patterns 
that were repeated, thus offering recurrent models of the same material that could serve as further opportunities for imitation. The passage will be divided into two approximately equal parts to ensure that both partners read and shadowed the same number of words.

\subsection{Method of data Collection}

\subsubsection{Classroom observation}

The researchers attend the teaching and learning process to gather the students to use the data about comprehension strategies during shadow reading. Mills and Gay (2015) stated that in observation the researchers obtain the data by merely watching the participant. In this part, the researchers will observe and record the students' activities in the classroom. The classroom observation will conduct in three meetings.

\subsubsection{Audio-video recording}

The researchers used audio and video recordings to record actual interactions during shadow reading. The audio recording provided a verbal expression of the students during shadow reading. Moreover, video recording also offered activities in the classroom.

\subsection{Procedure Data Collection}

- Firstly, the researchers visited the school to make a deal about the research.

- The researchers met the headmaster and English teachers to determine the available time to conduct the research.

- The researchers asked for permission to the English teacher to use their class

- The researchers asked the English teacher to implement shadow reading in she/he classes.

- The researchers gave the concept of shadow reading before starting the class

- During the learning process, the researchers observed and took video until the end of class

\subsection{The Technique of Data Collection}

The data was collected by using qualitative data collection. According to (Bogdan \& Biklen, 2007), qualitative data collection involves spending considerable time in the setting under study, immersing oneself in this setting, and collecting as much relevant information as possible. In this research, there is only one method namely observation. The observation was conducted to find out the reality of the factual situation of shadow reading activity. Marshall and Rossman (2014) state that through observation the researchers learn about behavior and the meaning attached to those behaviors. In observation, researchers obtain data by merely watching the subjects. The emphasis during observation is on understanding the natural environment as lived by participants, without altering or manipulating it (Mills \& Gay, 2015). Therefore, the researchers did observations with the help of audio-video recording to provide factual data about students' strategies to comprehend narrative text during shadow reading.

\subsection{The Technique of Data Analysis}

Qualitative data analysis is the process in which moving the raw data that have been collected as part of the research study into some forms of explanation, understanding, and interpretation of the phenomenon, people and situation that are investigating (Chowdhury, 2015). Also, Creswell (2012) states that analyzing qualitative data requires understanding how to make sense of the text and images so that they can form answers to the research questions. In other words, qualitative data analysis involves the identification, examination, and interpretation of qualitative data and determines how the data help to answer the research questions. The data analysis in this research was based on Miles, Huberman, and Saldana, (2018) who propose that qualitative data analysis consists of three concurrent flows of activities namely data condensation, data display, and conclusion drawing/verification.

\subsubsection{Data condensation}

Data condensation is the process of selecting, focusing, simplifying, abstracting, and transforming the data that appear in the full body of written-up field notes, interview transcripts, documents, and other empirical materials. It means that the qualitative data obtained was transformed into textual data (transcripts). Then, the researchers identified and choose the most important part which is relevant to the topic. Therefore, the analysis focused on the selected data which is suitable for the research questions that have been formulated.

\subsubsection{Data display}

The second significant flow of analysis activity is data display. The display means organized information that leads the researchers to conclude. Data display showed based on the research focus. It includes displaying data in written text in terms of extracts.

\subsubsection{Conclusion drawing/verification}

The third flow of analysis activity is conclusion drawing and verification. The conclusions were based on the data display to answer the research questions regarding the strategies used by students during shadow reading. Moreover, the researchers verified the conclusions to obtain a better understanding. The three types of analysis and the data collection form an interactive process. Therefore, the researchers steadily moved among these four nodes during data collection and then shuttles among condensing, displaying, and conclusion drawing/verifying for the remainder of the research. For example, the coding of data (data condensation) leads to new ideas on what should go into an extract (data display). Entering the data requires further data condensation. As the extract fills up, preliminary conclusions are drawn, but they lead to the decision, for example, for adding another extract to test the conclusion (Miles et al., 2018). Figure 1 below shows the interactive model of the data analysis. 


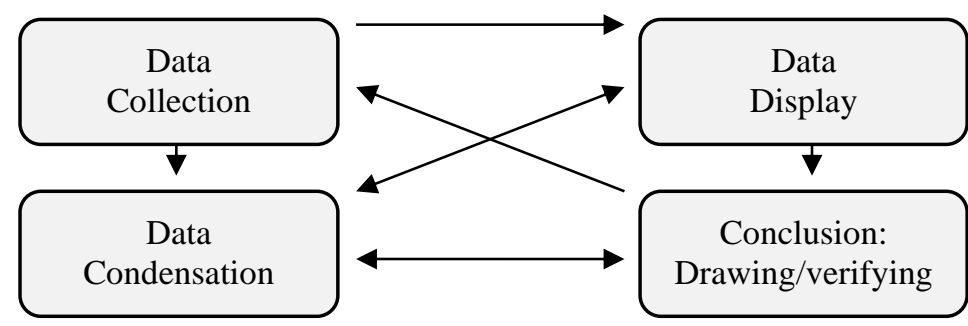

Figure 1. Interactive model of data analysis

\section{FINDINGS}

The data presented was taken from the recordings of during reading activities in the classroom. The data was used to find out comprehension strategies used by the students during shadow reading activity. Notably, the researchers showed the results by displaying extracts for each strategy used by students during shadow reading. The notation system used in the transcript in this research follows:

$\mathrm{R} \quad$ : Reader's oral reading of the text or commenting during tasks.

$\mathrm{S} \quad$ : Shadower's repetition or comments during tasks.

Bold : inserted comments, questions, requests, errors, other corrections, modifications

(parentheses) : translations/explanations provided by researchers.

[brackets] : phonetic transcriptions

\subsection{Phonological processing strategies used by the students during shadow reading}

Based on data analysis, the researchers found two strategies of phonological processing focus. In this case, there are some problems identified by the students during shadow reading about phonological processing. Some words are difficult to pronounce. Thus, the students create mispronunciation. The students identify the problems, and they use strategies to help their partner to comprehend the utterance.

\subsubsection{Repairing incorrect utterance (self and other)}

Extract 1:

(247) R: [Nou]. eh...['nau] (now) he goes to a different school.

(248) S: Now he goes to a different school.

(249) Now. he goes to a different school.

Extract 1 above was taken from the transcription of partner 7. It shows that the reader made an error in pronunciation (mispronounce) of the word 'now.' The reader creates mispronounce of the word 'now' because of his/her L1. But, the reader recognizes the word and makes self-correction directly by continuing the sentence. In this case, the reader uses phonological processing strategies by repairing the utterance (self-correction).

\subsubsection{Dividing a word in manageable sound (segmenting)}

\section{Extract 2}

(554) R: Bob Miller is happy at his new school.

(555) S: Bob Miller is happy at his new school.

(556) Bob Miller is happy at his new school.

(557) R: The students are friendly.

(558) S: the students are...friend...apa?

(559) R: friend-ly

(560) S: The students are friend-ly.

(561) the students are friendly.

Extract 2 above was taken from a transcription of partner 13. It shows that the shadower finds difficulties in uttering the word 'friendly' and ask for the right word by pausing the incomplete word. After that, the reader continues the incomplete word by segmenting the word into two syllables 'friend-ly.' Then, the shadower can repeat the sentence after segmenting the word. In this case, the reader uses phonological strategies by dividing the word into manageable sound to help his/her partner.

\subsection{Word recognition strategies used by the students during shadow reading}

Based on data analysis, the researchers found two strategies of word recognition focus. In this case, there are some problems identified by the students during shadow reading about the word recognizing. Some words are difficult to recognize. Thus, the students need assistance to complete the task. Therefore, the students use strategies by asking for assistance to their partner in two ways (directly and indirectly).

\subsubsection{Implicitly asking for assistance to complete the task}

\section{Extract 3}

(359) R: He asks another student, "Why do some students call me Eddy?" 
(361) R: he asks another student.

(362) S: he asks another student

(363) R: "Why do some students call me Eddy?"

(364) S: "why do some students call me Eddy?"

Extract 3 above was taken from the transcription of partner 9. It shows that the shadower finds difficulties to recognize some words of the sentence. The shadower asks for assistance indirectly by pausing some words in the sentence. The reader understands the missing words. Thus the reader can repeat the sentence by dividing the sentence into two to help the shadower in completing the task. In this case, the shadower uses word recognition strategies by asking for assistance implicitly to complete the task.

\subsubsection{Giving repetition for incorrect word recognition \\ Extract 4 \\ (255) R: One day, Bob meets Eddy Garland. \\ (256) S: Monday, Bob meets Eddy Garland. \\ (257) R: One...day... \\ (258) S: one satu? \\ (259) R: yes \\ (260) S: one day. apalagi \\ (261) R: one day, Bob meets Eddy Garland. \\ (262) S: One day, Bob meets Eddy Garland.}

Extract 4 above was taken from the transcription of partner 7. It shows that the shadower could not recognize the words "one day" and creates "Monday." The reader recognized the incorrect word and repeated the right words. In this case, the reader uses word recognition strategies by giving repetition for incorrect words to help the shadower in completing the task.

\subsection{Syntactical processing strategies used by the students during shadow reading}

Based on data analysis, the researchers found two approaches to syntactical processing focus. In this case, there are some problems identified by the students during shadow reading about syntactical processing. Some words are difficult to identify because of organization units. The students tend to shadow in incomplete sentences and need assistance to complete the task.

\subsubsection{Modifying input for manageable repetition by chunking}

\section{Extract 5}

(702) R: When the boys were born,

(703) the Miller family adopted Bob,

(704) and the Garland family adopted Eddy.

(705) S: When.

(706) R: when the boys were born,

(707) S: when the boys were born

(708) when the boys were born

(709) R: The Miller family adopted Bob,

(710) S: The Miller family adopted Bob

(711) the Miller family adopted Bob,

(712) R: and the Garland family adopted Eddy.

(713) S: and the Garland family adopted Eddy.

Extract 5 above was taken from a transcription of partner 16. It shows that the shadower finds difficulties in shadow the complex sentence. So, the reader use strategy to divide the complex sentence into shorter clauses. After reading the shorter clauses, the shadower can repeat the sentence successfully. In this case, there is a modification of inputs from complex sentence to simple sentence.

\subsubsection{Explicitly requesting for repetition (chunking)}

\section{Extract 6}

(1388) R: Later Bob and Eddy find out that they have another brother.

(1389) S: ulangi! Kepanjangan

(1390) R: Later, Bob and Eddy find out

(1391) S: Later Bob and Eddy find out

(1392) R: that they have another brother.

(1393) S: that they have another brother.

Extract 6 was taken from the transcription of partner 30. It shows that the shadower cannot recognize the complete sentence and shows directly that the sentence is long enough to repeat. In this case, the shadower also requests the repetition directly to complete the task. Then, the reader chunks the sentence into two clauses. In this case, the shadower can repeat the sentence properly after his/her request was done. 
Table 1 The summary of the comprehension strategies used by the students during shadow reading

\begin{tabular}{ll}
\hline \multicolumn{1}{c}{ FOCUS } & \multicolumn{1}{c}{ STRATEGIES } \\
\hline $\begin{array}{l}\text { Phonological processing: to recognize a word through } \\
\text { pronunciation }\end{array}$ & $\bullet$ Repairing mispronunciation (self and other) \\
\hline $\begin{array}{l}\text { Word recognition: to identify a word that is missed in the task } \\
\text { because of difficulty in pronunciation and meaning }\end{array}$ & $\bullet$ implicitly requesting repetition to complete the task \\
\hline $\begin{array}{l}\text { Syntactical processing: to arrange words, phrases, and } \\
\text { sentences to structure the text into a meaningful whole }\end{array}$ & $\bullet$ Giving repetition for incorrect word recognition \\
\hline
\end{tabular}

Based on table 1, there are two comprehension strategies made by the students about phonological processing. They are repairing incorrect utterance (self and other) and segmenting. In this case, there is a difference between this research result and the previous study. There is no aiding complete the task of phonological processing. The students tend to help their partner directly without helping. While in syntactical processing, the students tend to modify their input and requesting repetition to complete the task. Also, there are no comprehension strategies which focus on orthographic processing and lexical access.

\section{DisCUSSION}

The discussion of this research deals with the interpretation of the results derived from transcription of audio video recording. There is a critical aspect in this research namely comprehension strategies used by the students during shadow reading. Based on the result above, there are six comprehension strategies used by the students during shadow reading. They are focused on three important aspects of reading namely phonological processing, word recognition, and syntactical processing. Those aspects are used to identify the strategies used by the students during reading to help students in comprehending narrative text. Moreover, Fountas and Pinnell (2001) claim that comprehension is not something that happens after reading.

This research uses the basis of comprehension enabling talk analysis during shadow reading by de Guerrero and Commander (2013). In their study, there are five focus on comprehension namely, phonological processing, orthographic processing, word recognition, lexical access, and syntactical processing. From five comprehension focuses, there are fourteen strategies identified during shadow reading. But in this research, there are only six strategies identified. However, in this study just focus on the comprehension strategies. Thus there are only three comprehension focuses identified namely phonological processing, word recognition, and syntactical processing. Based on phonological processing strategies above, it can be concluded that the students can identify mispronunciation and fix it by themselves or correct their partner. It shows that the students have phonemic awareness and can use appropriate strategies to complete the shadow reading activity. When the tasks of shadow reading are fulfilled, and the shadower can shadow successfully, it means that the students are in ZPD. In this case, both the reader and the shadower were helping each other and received comprehensible input from their partner. Thus, they can complete the task.

Furthermore, in word recognition strategies, the students can recognize the missing and incorrect word of their partners. They also use strategies to fill the missing word and correcting their partner through repetition. Firstly, the shadower found out the problem to recognize the word. In this case, the reader helps the shadower to complete the task, and it shows that the shadower is in ZPD. While in syntactical processing strategies above, it can be concluded that the shadowers used direct request in their first language to get comprehensible input while the readers are giving repetition to the incorrect word that is created by the shadowers. After repeating the correct words, the shadower can complete the task and is in ZPD. During analyzing the transcriptions of recordings, the researchers did not identify any orthographic and lexical access strategies, especially in orthographic processing; the researchers use no challenge in the text. Although, another study makes some changes to challenge the reader to find out more strategies because related changes to words have been used in the second language assessment to uncover decoding deficits (Pulido, 2007). However, the researchers keep the original text to find natural strategies created by the students during shadow reading.

\section{CONCLUSION}

There are three foci in this research related to comprehension strategies used by the students during shadow reading namely phonology, word recognition, and syntax. From the three attentions, the researchers find out six comprehension strategies during shadow reading namely, repairing incorrect utterance of partner (self and other), dividing a word in manageable sound, giving repetition for incorrect word, implicitly asking for repetition, modifying input for manageable repetition and explicitly requesting for repetition.

\section{REFERENCES}

Berk, L. E., \& Winsler, A. (1995). Scaffolding Children's Learning: Vygotsky and Early Childhood Education. NAEYC Research into Practice Series. Volume 7. ERIC.

Bogdan, R., \& Biklen, S. K. (2007). Qualitative Research for Education: An Introduction to Theories and Methods. Pearson A \& B. Retrieved from https://books.google.co.id/books?id=HSMiAQAAIAAJ

Bolain, J. (2008). Reading Comprehension Level of Grade VA Pupils Using KWL Strategy. Gabagan: Isabella.

Chowdhury, M. F. (2015). Coding, sorting and sifting of qualitative data analysis: Debates and discussion. Quality \& Quantity, 49(3), 1135-1143.

Commander, M., \& de Guerrero, M. (2016). Shadow-Reading: Guidelines for a Socially-Mediated Approach to Reading in the Second/Foreign Language Classroom. The Reading Matrix: An International Online Journal, 16(1), 32-48. 
Creswell, J. W. (2012). Educational Research: Planning, Conducting and Evaluating Quantitative and Qualitative Research. Educational Research. Pearson.

de Guerrero, M. C., \& Commander, M. (2013). Shadow-reading: Affordances for imitation in the language classroom. Language Teaching Research, 17(4), 433-453. https://doi.org/10.1177/1362168813494125

Fountas, I. C., \& Pinnell, G. S. (2001). Guiding Readers and Writers, Grades 3-6: Teaching Comprehension, Genre, and Content Literacy. ERIC.

Grellet, F. (1981). Developing reading skills: A practical guide to reading comprehension exercises. Cambridge University Press.

Hamada, Y. (2012). An effective way to improve listening skills through shadowing. The Language Teacher, 36(1), 3-10.

Heyer, S. (1987). True stories in the news: A beginning reader. Longman.

Marshall, C., \& Rossman, G. B. (2014). Designing Qualitative Research. SAGE Publications. Retrieved from https://books.google.co.id/books?id=qTByBgAAQBAJ

Miles, M. B., Huberman, A. M., \& Saldana, J. (2018). Qualitative Data Analysis: A Methods Sourcebook. SAGE Publications. Retrieved from https://books.google.co.id/books?id=fjh2DwAAQBAJ

Mills, G. E., \& Gay, L. R. (2015). Educational Research: Competencies for Analysis and Applications. Pearson. Retrieved from https://www.amazon.com/Educational-Research-Competencies-Applications-Standalone/dp/0133972062

Murphey, T. (2001). Exploring conversational shadowing. Language Teaching Research, 5(2), 128-155. https://doi.org/10.1177/136216880100500203

Pulido, D. (2007). The relationship between text comprehension and second language incidental vocabulary acquisition: A matter of topic familiarity? Language Learning, 57, 155-199.

Sadeghi, E., Afghari, A., \& Zarei, G.-R. (2016). Shadow-Reading Effect on Reading Comprehension: Actualization of Interactive Reading Comprehension: (A Vygotskyan View!). English Language Teaching, 9(3), 130-138.

Shafiei, M., \& Rahmany, R. (2017). The Effectiveness of Shadow-Reading with and Without Written Script on Pronunciation of Iranian Intermediate EFL Students. Journal of Teaching English Language Studies, summer (6), 39-52.

Vygotsky, L. S. (1980). Mind in society: The development of higher psychological processes. Harvard university press.

Vygotsky, L. S. (1986). Thought and language-Revised edition. The MIT Press. 